\title{
Impact of Application of the Training Strategy on Improving the Efficiency of the Employees' Performance in Zarqa University
}

\author{
Dr. Ibrahim Mohamed Khurais \\ Associate Professor / Department of Economics, \\ Faculty of and Administrative Sciences / Zarqa University \\ i_khrais_economic@yahoo.com
}

\begin{abstract}
The study aimed to identify the impact of application of the training strategy on improving the efficiency of the employees' performance in Zarqa University. The study population consisted of all employees in Zarqa University, were chosen as a proportionality stratified random sample consisting of (50) employee, and was distributed the study questionnaire on them. The study found a number of results most notably were:

- The results of descriptive analysis indicated to high the averages of the training strategy items. These results indicate that the employees responses in Zarqa University on these items were (positive), and this means that the level of evaluation of the items of the mentioned variable ranged between (medium \& high) from their perspective.

- The results indicated that there exist a statistically significant impact at a significant level $(\alpha=0.05)$, for application of the training strategy on improving the efficiency of the employees performance in Zarqa University.
\end{abstract}

The study concluded that a number of the recommendations and conclusions.

Keywords: Training strategy, Performance efficiency, Zarqa University, Jordan.

\section{INTRODUCTION}

The training is no longer a limited to the holding of training courses and the granting of passing these courses certificates, it has become a strategic choice for the development of human resources, where the individual was considered one of the most important resources that underpin the foundations of the development and construction and development, so the scientists cared in various disciplines to the individual human and fired by the name (human capital).

The employees are the human capital for the facility, which must be refine talents and abilities of the physical and mental, to make them more efficient and ability to deal with the technological era variables, which will reflect the best image on the desired performance, so the successful training is able to reach this objective.

So, the choice of the individuals with high abilities in working alone is not sufficient to ensure the accomplishment as required, but needs to be another factor that is considered one of the duties of the facility which create the sufficient incentive to have in order to achieve that accomplishment.

\section{METHODOLOGY}

\subsection{The Study Problem and its Questions}

In spite of the importance and role which played by the employees to provide the business well for students and the local community, however, including those who do not possesses the ability to perform the businesses well due to lack of experience and training. Thus, the study problem summed up in answer the following questions:

1. What the level of application the training strategy in Zarqa university from the perspective of their employees?

2. Is there an impact of application of the training strategy on improving the efficiency of the employees' performance in Zarqa University? 


\subsection{The Study Importance}

The importance of this study was the fact that Zarqa University depend upon completely on its human resources who are dealing directly with the students and local community in all fields, as well as the importance of having the plans and training programs to prepare these cadres to suit the conditions of the university and its possibilities, and keep abreast of the technological developments to improve and develop the performance of its employees.

\subsection{The Study Objectives}

This study is mainly aimed to measure the impact of application of the training strategy on improving the efficiency of the employees' performance in Zarqa University, and through the following subobjectives:

- To identify the training concept and its importance and objectives.

- To identify the preparation mechanism of the training programs in Zarqa University.

- To measure the impact of application of the training strategy on improving the efficiency of the employees performance in Zarqa University.

- The possibility of reaching to results from which to formulate some recommendations that will assist the decision-makers in Zarqa University to achieving the training strategy concept, because of its positive impact on improving the efficiency of the employees' performance in Zarqa University.

\subsection{The Study Model}

In light of the study objectives was to propose the following study model, for the purpose of analyzing the impact of application of the training strategy on improving the efficiency of the employees' performance in Zarqa University. As shown in the following figure No. (1):

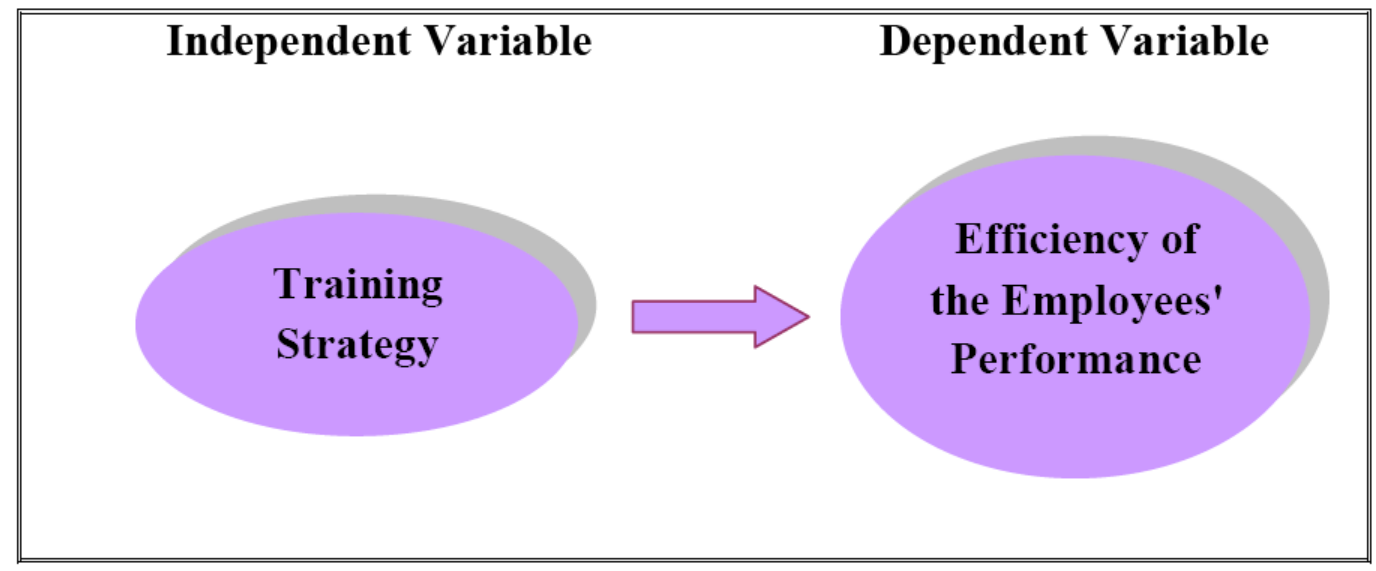

Figure1. Study Model

Source: Prepared by the researcher.

\subsection{The Study Hypothesis}

To achieve the study objectives, the researcher develop the hypothesis as follows:

$\mathbf{H}_{0}$ : There is no a statistically significant impact at the significant level $(\alpha \leq 0.05)$, for application of the training strategy on improving the efficiency of the employees' performance in Zarqa University.

$\mathbf{H}_{1}$ : There exist a statistically significant impact at the significant level $(\alpha \leq 0.05)$, for application of the training strategy on improving the efficiency of the employees' performance in Zarqa University.

\section{THEORETICAL FraMEWORK \& LiTERATURE REVIEW}

\subsection{Theoretical Framework}

\subsubsection{The Training Concept}

In order to give a clear picture of the training concept, given the multiplicity and diversity of the definitions contained in the literature of scholars and interested, which came in response to variation 
ideological among thinkers on the one hand, and differing time and place between the communities on the other hand, and on this basis we will remember this simple definition for training: is (to teach the individual specific skills for certain purpose), and it appears from this definition: that the training aims to develop the ability of the individual (employee), the mental and physical, which lies in achievement the business assigned by employee in the best possible image of and the lowest cost, effort and time. In spite of the multiplicity of training concepts, but it contained:

- Structured Developing: Means, planned, organized and censorship.

- Individual: Means, it does not mean the groups or facilities.

- Performance: Means, accomplish any task or action.

- Institutional procedures: The sense that we are talking about a coordinated and planned processes.

- Maximize and strengthen the education: The sense that we seek to learning at the individual and institutional levels.

- Efficient of facility: The goal is the overall efficiency of the facility.

- Programmable process: Trying administration can improve the employee skills through increased knowledge.

- Continuous process: It is subject to the Acquisition of the skills and experience.

\subsubsection{The Training Objectives}

For each training program specific objectives are classified into general objectives and behaviorism objectives so that the measurement of the feasibility of the training and assessment depends entirely on the existence clear objectives from the facility which want them radically develop and bring about real development in the attitudes, concepts and skills of the employees in order to uplifted with the knowledge and professional experiences and the development of performance, followed by it is not possible design any training program and development of its contents, methods and determine the its duration without prior knowledge required to achieve the objectives of this program (Ayman \& et al., 2010).

The following general objectives and desired results of the training:

- Reduce the working costs and maintain the devices and maintenance.

- Increase the level of job satisfaction among the employees, while meeting their training needs and minimize the psychological pressure on them.

- Reduce the absence rate of the employees from work.

- Raise the level of productivity and improvement of the quantitative and qualitative terms.

- Use the training as a method of motivation, promotion and meritocracy methods.

- Use sensitize of the importance of the employees training, and equip them with the ability to search for new, and not to rely on controlled (i.e., there is an internal control of the employee).

- Minimize the turnover rate for the employees.

- Reduce the time and effort.

- Make a positive impact on employees behavior.

- Training plays an active role in reducing the gap between the capacity of the employees they own and the nature of the businesses to be performed.

- Increase the sales.

- Defined of the employees by the scientific, technological and economic developments. 


\subsubsection{The Training Justifications}

- Increase in the numbers and types of goods and services that compete with each other in order to get a larger market share.

- The rapid development of the industrial plants and dependence on the modern technology.

- Developments of the various environmental.

- The great development of means of the communication and transport.

- Intension desire of the employees to get extra inputs as a result of the evolution of their performance level.

\subsubsection{Stages of Training Preparing}

There are several stages that represent the basics of the training, preparing, among them the following:

- Identify needs of the training: Collection of information on the training needs and any of the new skills required by the facility.

- Identify the training requirements: What are the attitudes that need to be developed.

- Identify the training objectives: What do expect from his employees after completion the training program.

- Development of the training programs: Use the right mix of technologies, methods, equipment and the training locations.

- Determine the training organizers: Determine whether they are coaches from within the company or external consultants.

- Determine the requirements for the training: Determine the locations and the facilities, appropriate technology in order to enable apprentices to acquire the skills, knowledge and attitudes that they need.

- Implementing and evaluating the training: Implementation of the special programs that have been prepared for training, and then evaluate the results of training is they compatible with the objectives of the training realism.

\subsubsection{The Training Importance}

Training is to become a cornerstone of the main solution to provide a capable labor to perform the work tasks, where the training aims to give the individuals the information, the knowledge and the skills required by the job and practice applied, in addition to the development of this information, knowledge and the skills commensurate with the desired change in both current employment or jobs emerging or tasks the development of the employee's performance and abilities in performing these tasks, and the special objectives or specific basis are placed to meet the training needs of the concerned represented by the problems facing companies in the framework of the development of human resources and with diversity of these problems are numerous requirements, the design of the various training programs.

\subsubsection{The Training Importance for Facilities}

Training of great importance in the era we live in, so that the scientific and technological development is rapid, so we consistently need to learn the skills and new sciences, and need only to employees training to raise their efficiency to work under the prevailing circumstances, but beyond that to achieve a group of other objectives (Douglas \& et al., 2010):

- Reduce the labor turnover rate.

- Raising the morale of the employees.

- Improving the relations with citizens.

- Increase the ability to time and cost management.

- Raising the experience and skill level. 


\subsubsection{The Training Importance for Employees}

The training must be permanent and continuous process for employees, especially in the twenty-first century, where there are plenty of economic and technological variables, so the employees need to adapt and appropriate to suit their way of these variables. The main benefits of employees training can be summarized as follows (Al-Sumaidaie \& et al., 2007):

- Improving employee performance: The apprentice worker will work very efficiently and effectively.

- Minimize the Cost: The employee's work with high efficiently and effectively, the cost will be reduced.

- Reduce the labor turnover rate: The worker self-assured, estimated support and motivation provided by the company to him it is not considering a move to another company.

- Improving the motivation: The good training assist the employee to stay a catalyst, for his confidence in his abilities.

- Minimize the audit and oversight: The employee can trainer well its management and actions well, which means that the administration will spend less effort in the supervision and therefore shall supervise all to continue.

\subsection{Literature Review}

The following is a summary of the most important studies related to the subject of this study:

- Study of (Ayman \& et al., 2010) entitled: Impact of the training on the employees performance in the insurance sector.

The study aimed to identify the impact of the training on the employees performance in the insurance industry, also aimed to identifying on the role of the variables of the study (job position, educational qualification, experience years, and number of the training courses) on the study subject. The study sample consisted of a number of employees in the insurance sector in Nablus city, such that the researchers selects the sample as randomly from the study population, the researchers developed a questionnaire to measure the impact of the training on the employees performance in the insurance sector, and included a statistical analysis of the data using the test (t), and (one-way analysis of variance) to analyze a the study data, in addition to the averages and standard deviations. The study found a number of results, including the following:

- There exist a statistically significant relationship at the significance level $(\alpha=0.05)$, between the training and improve performance at work.

- There exist a statistically significant differences at the significance level $(\alpha=0.05)$, in the respondents' responses about the performance before and after training.

- The training implies to increase the spirit of belonging to the company and improve the quality of services that provided by the employees in the insurance sector.

- The level of benefit from courses held externally more than one level to take advantage of courses held locally.

- Study of (Al-Fuqaha \& Ahmed, 2010) entitled: Impact of the training on the employees' performance in the private sector.

The study aimed to identify the impact of the training on the employees performance in the private sector in Nablus city, also aims to identify some of the variables of the study such as (training, employee performance, skills and technical capacity, quality of service quality, and spirit of belonging). In order to achieve the study objective, the researchers developed a tool consisting of (35) items has been distributed on the sample of (60) individuals, after collection the data has been coded and entered into a computer and processed statistically using the Statistical Package for Social Sciences (SPSS). The study results indicated to the existence of large approval degrees on the items and the study question the which is: What is the impact of the training on the employees performance in private companies, and also pointed to a relationship between the training and performance of 
employees, technical skills and abilities that they own, the quality of services provided, and spirit of belonging as dependent variables. In light of the results of the study, the researchers recommended the following:

- Work of extensive and thorough study on the subject of training and its impact on employees in Palestinian institutions.

- Necessity of adopt the principle of renewal in the training and not to repeat it, given the large of its importance on individuals and their career performance as well as to develop the quality of services provided by the private sector.

- Working to meet the employees' needs psychological, social and material through the reconsideration of the salaries, bonuses and incentives offered to them as well as the attention ladder promotions and because of its great impact on entrench spirit of belonging to them.

- Necessity of benefiting from the experience of successful countries and communities in the area of the functional training in public and private institutions have and try to take lessons from these experiences in order to achieve the institutional interest in the Palestinian areas.

- Study of (Abdelgadir \& Elbadri, 2010) entitled: Training Practices of Poland Banks: An Appraisal and Agenda for Improvement.

The study aimed to identify the training practices in the Poland commercial banks, the study data collection been required for the completion through selection of (30) commercial banks. To achieve the study objectives were prepared and design a questionnaire included on the training activities of (identifies training needs, develop training programs, and evaluate the effectiveness of training programs). The study found a number of results most notable was the following:

- Ignore the large number of Poland commercial banks included in the study for the identification process of the training needs when planning for banking activities.

- Absence of the process of evaluating the effectiveness of training programs results and its impact on the employees' performance in the Poland commercial banks.

- Study of (Kock \& Ellström, 2011) entitled: Formal and Integrated Strategies for Competence Development in SMEs.

The study aimed to identify the training programs strategies offered for the employees in a number of small and medium-sized business organizations in Sweden to develop the competencies they have. The study depended on a questionnaire as a tool to collect data from (14) small and medium business organization. Through survey some previous studies on the study subject, we can see the apparent lack of studies on the training function from a strategic entrance, also note the absence of studies on the impact of this entrance on the competencies in general and behavioral competencies, in particular, and therefore this study is to fill this shortage. The study found a group of the results was the most important:

- The study results indicated that the training needs to improve the learning environment in the organizational climate in order to come the desired results from it to improve the competencies required for the completion of work distinct.

- Existence of a statistically significant impact at the significance level $(\alpha=0.05)$, for the training programs to improve the employees competencies in the small and medium-sized business organizations in Sweden.

\section{Methods AND Procedures}

\subsection{The Study Approach}

The study used the descriptive and analytical approaches for the completion of this study, it was used descriptive approach to describe evaluation the training strategy in Zarqa university from the perspective of their employees, as the study was use the analytical approach to measure the impact of application of the training strategy on improving the efficiency of the employees performance in Zarqa University. 


\subsection{The Study Population and its Sample}

The study population consists of all employees in Zarqa University. The researcher was selected as a stratified random sample and distributed (60) questionnaires were retrieved (54) questionnaire, with reaching retrieval percentage of $(90 \%)$, after perusing the questionnaires of recovered were excluded (4) questionnaire, including the lack of information contained therein, and thus the number of valid questionnaires for statistical analysis (50) questionnaire, and the percentage was (92.6\%) from the retrieved questionnaires number.

\subsection{The Study Tool}

To achieve the objectives of the study, and after returning to the administrative literature, the tool is designed to describe the training strategy items and its impact on improving the efficiency of the employees performance in Zarqa University. The tool consisted of three parts, the first part of which dealt with the personal and functional information, while the second part dealt with the training strategy, while the third part included the variable (employees' performance). And was used (Likert Scale) to measure the degree to evaluation the training strategy items. It was the adoption of a scale to measure the training strategy is divided into three levels, where the calculated cut-off grade by dividing the difference between the highest value of the scale (5) and the lowest value in it (1) at three levels, namely that the cut-off grade is $\{(5-1) / 3=1.33\}$. And thus the three levels as follows:

\begin{tabular}{|c|c|c|}
\hline Low evaluation degree & Medium evaluation degree & High evaluation degree \\
\hline $1-2.33$ & $2.34-3.67$ & $3.68-5$ \\
\hline
\end{tabular}

After that was measured the tool sincerity and its reliability, as follows:

\section{a. Tool Sincerity}

Has been verified the (Face Validity) of the study tool, and through the presentation to a group of arbitrators with expertise and knowledge of economics and administrative literature at Zarqa university, and was the aim of the arbitration verify the extent of items belonging to the study variables, an appropriate degree of drafting items Linguistically, Has been taking into account the comments of the arbitrators, where been modification reworded drafting some of items, so that the questionnaire is designed in its final form.

\section{b. Tool Reliability}

To check the questionnaire reliability, the stability coefficient was calculated for the tool (the internal consistency of the questionnaire items) using coefficient (Cronbch's Alpha) coefficient, and the reliability coefficient for the overall tool is (0.838), as shown in Table (1) the following:

Table1. Results of Reliability (Internal Consistency of the Questionnaire items)

\begin{tabular}{|c|c|c|c|}
\hline The Variables & N & Cronbach Alpha & Stability Ratio \\
\hline Training Strategy & 12 & 0.839 & $83.9 \%$ \\
\hline $\begin{array}{c}\text { Efficiency of the Employees } \\
\text { Performance }\end{array}$ & 8 & 0.755 & $75.5 \%$ \\
\hline Overall Tool & $\mathbf{2 0}$ & $\mathbf{0 . 8 3 8}$ & $\mathbf{8 3 . 8 \%}$ \\
\hline
\end{tabular}

\subsection{The Statistical Methods}

After that was finished of the emptying the data in the computer, were used some statistical descriptive and analytical methods, which its available in the Statistical Package for Social Sciences (SPSS), in order to answer the study question and test the hypotheses, So the statistical methods that were used for the purposes of the statistical analysis of data are:

- Means and Standard Deviations.

- Cronbch's Alpha Coefficient.

- Simple Linear Regression.

\section{RESUlt OF Statistical ANALYSIS AND ITS DisCuSSING}

The purpose of this section to present the results of statistical analysis of data subjects' responses of the study sample study, which was reached through the use of Statistical Package for Social Sciences 
(SPSS). To measure and evaluate the answers of the respondents about the study (impact of application of the training strategy on improving the efficiency of the employees performance in Zarqa University), the adoption of a standard test (3) out of (5) degrees . In order to present the study results it was classified as follows:

\subsection{Results Related to the Study Question}

What the level of application the training strategy in Zarqa University from the perspective of their employees?

To answer the study question, it has been calculated the means and standard deviations to evaluate the employees responses on each item of the training strategy. Table (2), indicates to the results of the employees responses of Zarqa University, about the degree to evaluate the training strategy:

Table2. Means and Standard Deviations for the training strategy items $(N=50)$

\begin{tabular}{|c|c|c|c|c|c|}
\hline No. & Items & Mean & $\begin{array}{l}\text { Std. } \\
\text { Dev. }\end{array}$ & Rank & $\begin{array}{l}\text { Evaluation } \\
\text { Degree }\end{array}$ \\
\hline 1 & $\begin{array}{l}\text { The training program contain on suitable } \\
\text { scientific methods. }\end{array}$ & 4.14 & 0.73 & 7 & High \\
\hline 2 & $\begin{array}{l}\text { The training courses increases of the } \\
\text { performance and the employees efficiency. }\end{array}$ & 4.23 & 0.66 & 6 & High \\
\hline 3 & $\begin{array}{l}\text { The training courses contribute to refine the } \\
\text { talents and abilities of employees. }\end{array}$ & 3.66 & 0.99 & 11 & Medium \\
\hline 4 & $\begin{array}{l}\text { The training courses contribute to modify the } \\
\text { individual behavior from the professional } \\
\text { side. }\end{array}$ & 4.02 & 0.65 & 9 & High \\
\hline 5 & $\begin{array}{l}\text { The training courses contribute to achieving } \\
\text { the university objectives and the employees. }\end{array}$ & 4.10 & 0.71 & 8 & High \\
\hline 6 & $\begin{array}{l}\text { The training courses contribute to improving } \\
\text { the performance of the work. }\end{array}$ & 3.98 & 0.84 & 10 & High \\
\hline 7 & $\begin{array}{l}\text { The training courses contribute to raising the } \\
\text { level of self censorship. }\end{array}$ & 4.26 & 0.66 & 4 & High \\
\hline 8 & $\begin{array}{l}\text { The Training courses contribute to the } \\
\text { qualitative improvement of the work. }\end{array}$ & 3.54 & 0.93 & 12 & Medium \\
\hline 9 & $\begin{array}{l}\text { The training is development your ability to } \\
\text { deal with others in your business. }\end{array}$ & 4.30 & 0.61 & 2 & High \\
\hline 10 & $\begin{array}{l}\text { Been using a variety of methods during } \\
\text { training in addition to the lecture style. }\end{array}$ & 4.36 & 0.56 & 1 & High \\
\hline 11 & $\begin{array}{l}\text { The training courses lead to reduced the } \\
\text { working turnover rate. }\end{array}$ & 4.24 & 0.66 & 5 & High \\
\hline 12 & $\begin{array}{l}\text { Getting the knowledge and information } \\
\text { through the training courses reinforced from } \\
\text { conviction of importance of the training. }\end{array}$ & 4.29 & 0.65 & 3 & High \\
\hline- & Training Strategy & 4.09 & 0.44 & - & High \\
\hline
\end{tabular}

The results in Table (2), refers to the means of the items of the training strategy ranged between (3.544.36), where the item (10) that (been using a variety of methods during training in addition to the lecture style) got on ranked (first) in terms of its importance for the employees in Zarqa University, an mean was (4.36) and a standard deviation of (0.56), and the item (8) that (have contributed training courses in the qualitative improvement of the work) came at ranked (12) and the last on ladder of priorities estimates of the employees in the mentioned university.

\subsection{Results Related to Test the Hypothesis}

The researcher will test the study hypothesis as follows:

$\mathbf{H}_{\mathbf{0}}$ : There is no a statistically significant impact at the significant level $(\alpha \leq 0.05)$, for application of the training strategy on improving the efficiency of the employees' performance in Zarqa University.

In order to test the validity of the study hypothesis was used the simple linear regression analysis. As shown in table (3) and (4) below:

Table3. Summary of Simple Linear Regression Model

\begin{tabular}{|c|c|c|c|c|c|}
\hline $\mathbf{R}$ & $\mathbf{R}^{\mathbf{2}}$ & $\mathbf{F}_{\text {Ratio }}$ & Sig. & df. & Tabulated (F) \\
\hline 0.323 & 0.105 & 5.606 & 0.022 & $(1,48)$ & 4.04 \\
\hline
\end{tabular}


The results in table (3) show that:

- Validity of simple linear regression is proven, this is asserted by the calculated value (F) (5. 597) which is greater than (4.04), and that the significance value $(0.000)$ is less than the significance level $(\alpha=0.05)$.

- The value of the $\left(\mathrm{R}^{2}\right)$ of $(0.105)$, refers to the training strategy, interprets the percentage $(10.5 \%)$ of the changes in the efficiency of the employees performance in Zarqa university.

Table4. Results of the Simple Linear Regression Analysis

\begin{tabular}{|c|c|c|c|c|}
\hline Independent Variable & Coefficients $(\boldsymbol{\beta})$ & $(\mathbf{t})$ value & Sig. & Standardized Coefficients (Beta) \\
\hline Constant $\left(\beta_{0)}\right.$ & 2.785 & 4.840 & 0.000 & - \\
\hline Training Strategy & 0.331 & 2.368 & 0.022 & 0.323 \\
\hline
\end{tabular}

Seen from the results in the table (4), the following:

- The statistical significant of regression coefficients $(\beta)$ for the training strategy is proven, therefore, there is a statistically significance impact at the significant level $(\alpha=0.05)$ for the training strategy on improving the efficiency of the employees' performance in Zarqa University. Depend on the statistical significant value (0.022), and the value is less than the significant level $(\alpha$ $=0.05)$, this means that the null hypothesis $\left(\mathrm{H}_{0}\right)$ is rejected.

- The value of the standardized coefficients (Beta) calculated for the training strategy which is (0.323), show that increase of the mentioned variable by a unity standard deviation will lead to efficiency of the employees' performance in Zarqa University by (32.3\%).

\section{CONCLUSIONS AND RECOMMENDATIONS}

This section deals with the most important conclusions of the study, also included on the most important recommendations of the study in light the results, which are as follows:

\subsection{Conclusions}

The study reached to a number of conclusions, among them the following:

- The results of the descriptive analysis explain that the evaluation level for the training strategy in Zarqa University was a (positive) from the perspective of their employees.

- The results of the descriptive analysis refers to weakness of (a contribution of the training courses in the qualitative improvement of the work), in the light of estimates and responses of the employees at University.

- There exist a statistically significant impact at the significant level $(\alpha=0.05)$, for the training strategy on improving the efficiency of the employees' performance in Zarqa University.

\subsection{Recommendations}

In light of the results, the study recommended the following:

- Necessity attention by the training process to take place before any training course to set specific and clear objectives for this process, which will reflect positively on the performance of the university employees.

- Concern by the findings which the study reached as aspects weakness in the training program for example, the item (a contribution of the training courses in the qualitative improvement of the work), which came in the last rank on ladder evaluate the study sample.

- The study suggests that necessity to conduct studies in the future to other universities or companies which uses variables differ from those variables of this study, and to use other statistical methods and taking into account a comparison of their results. 


\section{REFERENCES}

[1] Abdelgadir N. and Elbadri A., (2010), Training Practices of Poland Banks: An Appraisal and Agenda for Improvement, Journal of European Industrial Training, 25(2): 69-79.

[2] Ayman, Ghannam \& et al., (2010), Impact of the training on the employees performance in the insurance sector, Graduation research published on the net, Najah University.

[3] Abu Alnasr, Medhat, (2009), Phases of the training process (planning and evaluation of the training programs), Arab Group for the training and deployment, Cairo - Egypt.

[4] AS-Sumaidaie, Mahmoud, Al-Tai Hamid, Abu Hamida Omar, (2007), Activities of the training in the development of environmental skills, Paper presented to the seminar Association of Arab Universities held in (2007), Jordanian Zitouna University.

[5] Al-Kathi \& Hattab, Cima, (2010), A mechanism to identify the training requirements for new employees in a company-Takaful Palestinian for Insurance, Graduation research (unpublished), Najah University.

[6] Al- Moroccan, Abdul-Hamid, (2007), Modern Trends in studies and practices of human resource management, modern library.

[7] Douglas \& et al., (2010), Impact of the training on the productive efficiency of the employees in the vegetable oil factory in Nablus, Graduation research published on the net, Najah University.

[8] Ebrahim, Muhammad, (2009), Human Resource Management, University House, Alexandria, Egypt.

[9] Kock, Henrik and Ellström, Per-Erik, (2011), Formal and Integrated Strategies for Competence Development in SME's, Journal of European Industrial Training, 35(1).

[10] Touama H.Y., (2015), Statistical Tests: Bases and Applications, Dar Safa for Publishing and Distribution, Amman, Jordan. 